\title{
Sabiduría y bondad \\ Luis González, 1925-2003
}

\author{
Patricia Arias
}

C

omo saben, discípulos y amigos, don Luis gustaba de pensar en términos de generaciones, de ciclos largos y cortos que lo mismo afectaban los ritmos de la naturaleza que la trayectoria de los hombres. Con la creación de El Colegio de Michoacán, en enero de 1979, él tenía la certeza de que su propia vida - que había comenzado a transitar por su quinta década, lo cual lo había sumado al club de los pachichi-* había empezado también a dar un nuevo e importante giro que modificaría algunas de las sendas labradas entre 1946 y 1979, es decir, desde su ingreso como estudiante a El Colegio de México (Colmex) y la decisión de enfrascarse "en una acción novedosa" como fue la de fundar y presidir durante seis años (1979-1985) El Colegio de Michoacán en la ciudad de Zamora, Michoacán.

La modificación de sendas, en el caso de don Luis, fue, como casi todo en su vida, sin rupturas. Para muchos de

\footnotetext{
* En su discurso de inauguración de El Colegio de Michoacán contó que: "Los antiguos purépechas añadían al nombre propio de las personas, en el momento de cumplir los 52 años, el mote de patzitzi, que significa venerable en lengua y simplemente pachichi o arrugado en el idioma del pueblo."
}

sus colegas, discípulos y estudiantes siguió siendo el investigador, maestro, amigo ejemplar que habían aprendido a respetar y querer. Pero a ellos, don Luis comenzó a sumar un nuevo y cada vez más nutrido contingente de colegas y estudiantes de historia pero también de otros gremios — como el de la antropología — quienes entendimos, muy pronto, que nos encontrábamos no sólo con uno de los grandes de esa disciplina —en verdad, con "el mayor historiador de nuestra historia" como ha dicho Héctor Aguilar Camín— sino además con un creador de empresas culturales, de mano tan suave como firme, donde iba a poner a prueba mucho de lo aprendido en sus años de El Colegio de México pero también de las enseñanzas de una buena crianza pueblerina y de la relación cercana y afectuosa con personas que habían alcanzado la categoría de personalidades en muy distintos campos. Don Luis, además de un lector prodigioso y memorioso, fue siempre un observador acucioso que reflexionaba intensamente acerca de lo que veía y escuchaba.

La acumulación de obras, pero también de nuevos colegas y estudiantes, muchos de ellos convertidos en amigos en esa segunda fase de su vida, dan cuenta de lo que no cambió en don Luis: una biografía intelectual siempre

PATRICIA ARIAS: Universidad de Guadalajara. 


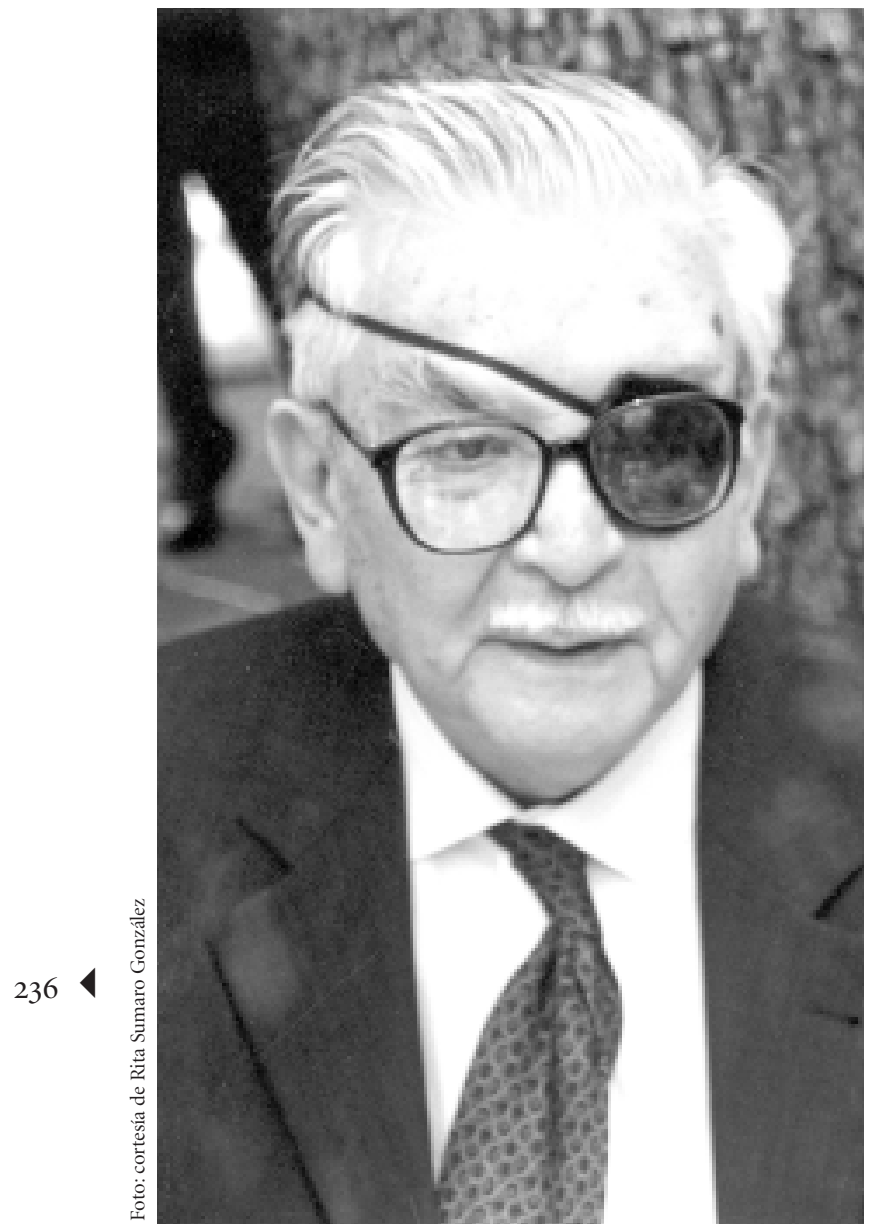

sabia, fecunda y original; una trayectoria personal invariablemente generosa e íntegra. En esos años, don Luis conjuntó y pulió quizá más que nunca dos atributos fundamentales: sabiduría y bondad, esas dos virtudes grabadas en el código genético transmitido por sus ancestros josefinos que él se encargó de acrecentar: la sabiduría de su padrino, el padre Federico González; la bondad de su padre, don Luis González Cárdenas.

\section{ANTES DE 1979}

Don Luis llegó al año 1979 con una serie de atributos y reconocimientos arduamente ganados que explican, sin duda, la oferta del entonces secretario de Educación Pú- blica, Fernando Solana, de que emprendiera la creación de una institución académica similar a El Colegio de México fuera de la capital del país.

Poco antes, en 1978, don Luis había pasado a formar parte de El Colegio Nacional. Con motivo de su ingreso al "Senado Cultural de la República, como lo llama la gente de voz recia", tuvo que elaborar, ayudado por sus estudiantes del Colmex, un apresurado curriculum vitae que, aunque él mismo reconocía incompleto, daba cuenta de lo que había sido su itinerario intelectual desde 1946 hasta 1978. Años más tarde, tuvo enfrente ese documento cuando, a pedido de Jean Meyer, escribió el capítulo "Luis González. Minuta de un viaje redondo" para el volumen Egohistorias. El amor a Clío.

Gracias a esos textos sabemos que su formación como historiador se inició en 1946 cuando ingresó a El Colegio de México. En términos formales, esa fase concluyó diez años más tarde, en 1956, cuando presentó la tesis La tierra y el indio en la República Restaurada, aprobada magna cum laude, con la que obtuvo el título de historiador y el grado de maestro en ciencias históricas por la Escuela $\mathrm{Na}-$ cional de Antropología e Historia. Entre esas dos fechas realizó una travesía inolvidable: entre los años 1951 y 1952 asistió a cursos en El Colegio de Francia y realizó estudios de posgrado en la Universidad de París, donde tomó clases con Marcel Bataillon, Ferdinand Braudel, Irénée Marrou, Maurice Merleau-Ponty, entre otros. Antes de regresar a México vivió varios meses en España donde conoció, trabajó y recogió materiales sobre la Nueva España en el siglo XVI en el Archivo General de Indias en Sevilla.

Pero su entrenamiento en el oficio había comenzado mucho antes y de la mejor manera o, si se quiere, como a él le gustaba, es decir, en la práctica. Por una parte, de la docencia. Desde 1943, cuando todavía vivía en Guadalajara, empezó a impartir clases en escuelas secundarias; más tarde en el ejército, cuando salió "agraciado" y le tocó hacer un año de servicio militar en la ciudad de México y, desde 1953, en las licenciaturas y posgrados del Centro de Estudios Históricos y el Centro de Estudios Internacionales de El Colegio de México y, en menor medida, en la Escuela Nacional de Ciencias Políticas y Sociales de la UNAM, en la Escuela Nacional de Antropología 
e Historia y en la Universidad Iberoamericana.

Entre 1954 y 1979 impartió innumerables cursos en los cuales vertió saberes y sumó discípulos. Aunque en sus primeros años como investigador tuvo cierta cercanía con temas prehispánicos y coloniales que se plasmaron en cursos como "Historia prehispánica de México", "Descubrimiento y conquista de México", "Historia colonial de México", fue más profusa y recordada su labor docente en cursos de asuntos generales - "Historia de la cultura", "Historia contemporánea del mundo", "Historia del Estado y la sociedad en México", "Seminario de lecturas de política mexicana”- y los que se refieren al siglo XIX y a la época contemporánea: "La revolución de Independencia en México", "Historia de México independiente", "Historia de México en el siglo XIX", "México en el siglo XIX", "México desde 1920", "El porfiriato", "La Revolución mexicana", "Problemas contemporáneos de México".

Sin embargo, él recordaba con agrado la impartición de cursos de índole teórico-metodológica - "Introducción a la historia", "Introducción a los estudios históricos", "Lecciones preliminares de teoría y método de la historia", "Teoría de la historia", "Teoría y método de la historia", "Teoría y práctica de la historia", "Filosofía crítica de la historia", "Técnica de la investigación documental", "El uso de la historia" - donde curiosamente había sido, decía, menos reconocido. Pero a partir de 1971, después del éxito de Pueblo en vilo, don Luis fue empujado a pensar y asediado para enseñar acerca de la microhistoria, asunto que se convirtió en una nueva veta de cursos, cursillos y conferencias.

Junto a su labor docente, don Luis se convirtió en lector, jurado y director de innumerables tesis. Él tenía la gracia de descubrir los intereses, habilidades, particularidades de los estudiantes y desde ese conocimiento los animaba a desarrollar sus investigaciones, más aún si se trataba de temas regionales a los que fue siempre particularmente sensible. Muchas de esas tesis se convirtieron en libros indispensables como La frontera nómada de Héctor Aguilar Camín, Los mexicanos que devolvió la crisis de Mercedes Carrera, La educación en Guadalajara durante la Colonia, 1552-1821 de Carmen Castañeda o Caudillos culturales en la Revolución mexicana de Enrique Krauze, por mencionar sólo algunos.
Pero las actividades académicas que don Luis mejor cultivó fueron, sin duda, la investigación y, siempre ligadas a ella, las publicaciones y la labor editorial. Todo comenzó muy pronto. En 1946, cuando fue admitido como alumno en el Centro de Estudios Históricos, empezó a convivir y aprender, dentro y fuera de los salones de clase, de maestros a los que guardó siempre tanto cariño como respeto: don Alfonso Reyes, que en ese tiempo era presidente de El Colegio de México; don Daniel Cosío Villegas, que era el secretario general, y don Silvio Zavala, que fungía como director del Centro de Estudios Históricos. Dos de ellos le recordaban, decía, a personas entrañables de su pueblo natal: don Alfonso Reyes, por su "actitud imperturbablemente comprensiva y conciliadora” a su padre, don Luis González Cárdenas, uno de los hombres más bondadosos de los que se tenga memoria en San José de Gracia; don Daniel Cosío Villegas, "hombre enérgico, sapiente y lúcido" se asemejaba al inteligente y carismático padre Federico González, tío de don Luis y líder moral indiscutible de la sierra de Jalmich. Don Luis apreció toda su vida también las enseñanzas de aulas y cafés de los maestros españoles trasterrados que fueron cobijados en el naciente Colegio de México.

Desde esos años, don Luis definió una característica central de su quehacer académico: jamás dejar un trabajo inconcluso, nunca dejar de entregar resultados publicables de sus investigaciones, grandes y pequeñas. En sus años de estudiante, entre 1946 y 1950, realizó seis "breves investigaciones” de tema prehispánico y colonial, que se publicaron en las revistas Estudios de Historiografía Americana, Revista de Historia de América y la flamante Historia Mexicana. Él reconocía que había sido "amasado para ser novohispanista, pero resulté chile de otros moles". En la contestación al discurso de ingreso de don Luis a El Colegio Nacional, don Silvio Zavala aludió a esos trabajos iniciales y lamentó que hubiera abandonado el estudio de esos periodos de la historia.

Sin duda, escribir se le facilitaba y mucho. Don Alfonso de Alba, compañero suyo en el Instituto de Ciencias en Guadalajara, recordaba la sorpresa que fue para maestros y compañeros darse cuenta de la originalidad y buena pluma que, recién llegado de San José de Gracia, demostró don Luis, en principio uno de los alumnos menos ilus- 


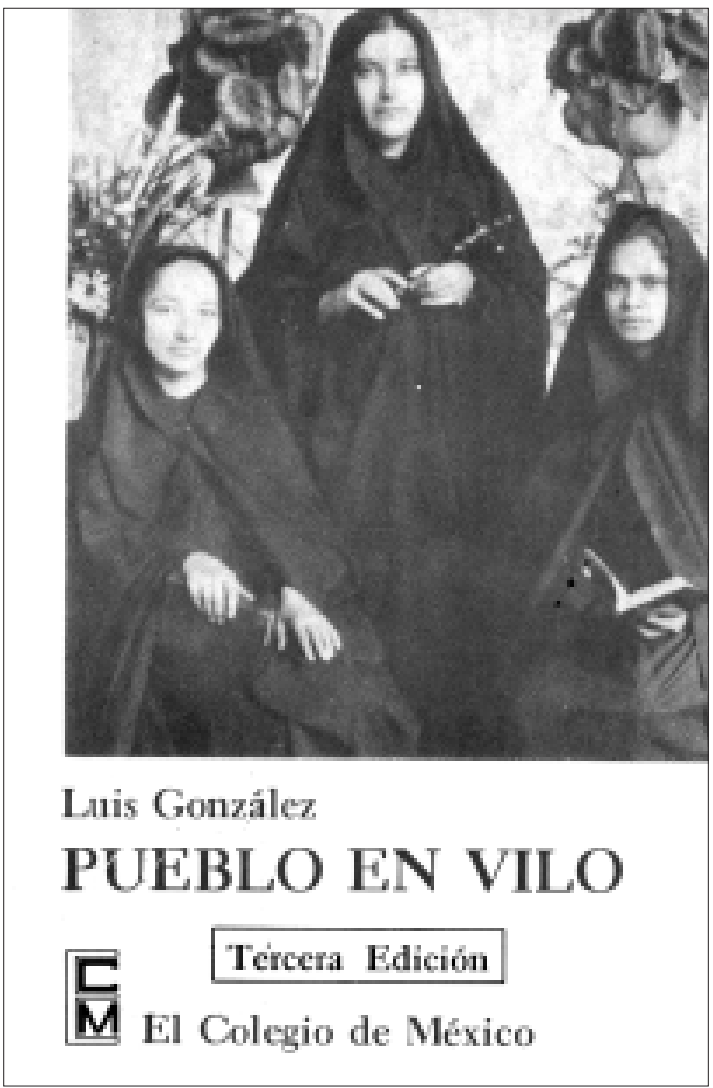

trados en ese colegio de niños urbanos acomodados. En sus primeros artículos elaborados en el Colmex, don Luis comenzó a integrar su extraordinaria habilidad literaria con el conocimiento de autores y teorías y el manejo de fuentes y materiales de primera mano recuperados en archivos, bibliotecas y hemerotecas.

Entre 1953 y 1955, don Daniel Cosío Villegas lo incluyó en un proyecto colectivo de investigación histórica y de formación de historiadores de largo aliento. En el "Seminario de historia de México" se buscaba, decía don Luis, "pulir investigadores e investigar exhaustivamente lo que don Alfonso Reyes llamó "el pasado inmediato de México", es decir, conocer a fondo el siglo XIX, la "centuria de las grandes agitaciones". Como es sabido, el ambicioso proyecto tuvo que ser acotado y restringirse a la etapa liberal y el porfiriato. Don Luis, en compañía de Emma Cosío, Armida de la Vara y Guadalupe Monroy, se encargó de investigar, documentar y escribir lo que se convirtió en el tercero de los nueve voluminosos tomos de la Historia moderna de México. La República Restaurada, dedicado a La vida social.

La tarea fue inmensa. Se trató de rastrear y dar cuenta de la parte más inexplorada de ese periodo, de lo que le había sucedido a las diversas sociedades del México de aquel tiempo y a la gente común más allá de los eventos políticos, es decir, se trataba de hacer una historia social "donde cuenta el grupo o la colectividad y poco o nada el hombre individualmente considerado; desaparecen los caudillos militar y político y la sociedad se convierte en el gran personaje de la tragedia o de la comedia históricas" aclaraba Daniel Cosío Villegas en la "Tercera llamada particular" que introduce el volumen en cuestión.

Don Luis cumplió la tarea encomendada con enorme profesionalismo y éxito. En La vida social se advierte, sin lugar a dudas, que era ya un maestro en el oficio de historiar. A todos queda claro que buscó, leyó, se documentó de manera personal y exhaustiva, que generó información y acuñó ideas que hacen de ese texto una obra titánica imprescindible. Se había convertido además en un maestro en la manera de narrar la historia entreverando argumentos y datos con propuestas teóricas claras de pluma irrepetible. La vida social está plagada de otra virtud de don Luis: su capacidad para sintetizar información e ideas y acuñar títulos y subtítulos tan atractivos como atinados.

A partir de este trabajo, don Luis dio rienda suelta a la certeza, invariablemente presente en sus obras posteriores, de que había que pensar al hombre inmerso en su geografía; de que había que hacer, siempre, una lectura histórica del paisaje que habitan, trazan, incluyen, eluden los hombres de cada sociedad en cada momento histórico.

Al mismo tiempo, gracias a su infinita capacidad de lectura y su memoria prodigiosa, acumuló conocimientos y reflexiones acerca de personas, lugares, periodos, documentos, estudios y temas que aparecieron publicados de distintas maneras en esos y los siguientes años. Imposible dejar de mencionar un artículo perfecto: "La sociedad jalisciense en vísperas de la Reforma” donde transformó la árida Estadística de Jalisco de don Longinos Banda en 


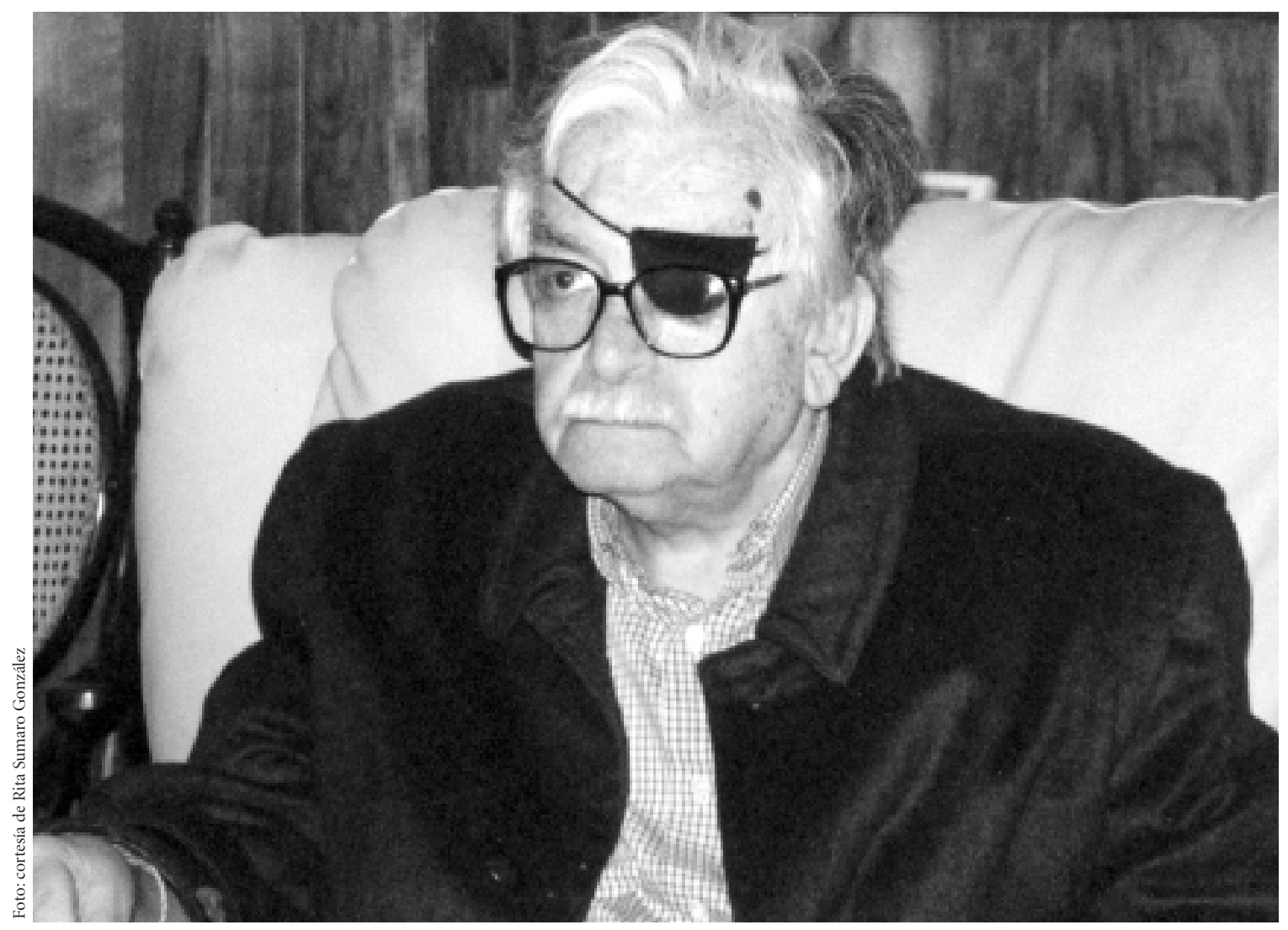

un retrato insuperable de la sociedad jalisciense, de la diversidad de sus paisajes, de su gente y sus intereses a mediados del siglo XIX. La recién fundada revista Historia Mexicana, entre otras publicaciones, se vio beneficiada de los excelentes artículos que emanaron de los trabajos realizados para la Historia moderna de México.

En verdad, don Luis reflexionaba y aprendía de todo lo que le sucedía. Las tribulaciones que pasaron para generar información social y regional para esa obra mayor los convencieron, a él y a don Daniel Cosío Villegas, de que no había "en México suficiente información sobre las provincias, ni documentos ni publicaciones periódicas ni libros siquiera" (Cosío Villegas, 1993: XXXIII), comprobación que estuvo muy presente en los intereses que definieron el rumbo de El Colegio de Michoacán.

En esos años entendió también que lo suyo era el trabajo personal. Que, aunque entendía y valoraba el traba- jo colectivo, para él "la narración histórica seguiría siendo obra individual de principio a fin". Hasta muy tarde en su vida aprovechó las madrugadas silenciosas para leer, marcar los libros con pequeñísimas rayitas, reflexionar, construir los esquemas a partir de los cuales comenzaba, ahí sí, a escribir. Para don Luis pensar y escribir eran dos actos diferentes que no había que mezclar ni confundir.

Poco después, y todavía en la línea de los grandes trabajos, se asoció con Luis Muro, Stanley Ross, Bertha Ulloa y Susana Uribe para "hacer el catálogo de lo escrito en México y sobre México en los treinta años que van de 1910 a 1940" de lo que resultó la obra, en cinco volúmenes, Fuentes de la historia contemporánea de México. Libros y folletos publicada por El Colegio de México en 1961-1962. En ese mismo "patín de erudito", decía, compiló documentos que formaron el abultado libro El congreso de Anáhuac publicado por el Senado en 1963. Más tarde, reunió 
y seleccionó los trabajos que conformaron los cinco volúmenes de Los presidentes de México ante la nación, publicado en 1966 por la Cámara de Diputados; estudio al que le amputaron, recordaba, el capítulo introductorio llamado "Balances presidenciales de la Revolución mexicana”. En 1973 se publicó un pequeño volumen colectivo —Historia mínima de México - elaborado en poquísimo tiempo, que se convirtió en un bestseller: ha sido traducido a quince idiomas y suma más de medio millón de ejemplares vendidos.

La confección de esas obras le afinaron aún más el olfato para descubrir y discriminar información; lo llevaron a perfeccionar su impresionante capacidad de síntesis; lo hicieron poseedor de conocimientos enciclopédicos; lo obligaron a trabajar mucho para lograr textos atrayentes a partir de cifras y documentos por lo regular áridos y de prosa obtusa. También lo volvieron conocido entre públicos más amplios, en especial los políticos, muchos de los cuales aprendieron a gozar de su prosa y a aceptar su irreverencia para referirse a héroes, sucesos y momentos consagrados por la historia de bronce.

Además de la elaboración de grandes obras y colecciones de documentos, don Luis publicó mucho en las décadas de 1950 y 1960. De esos trabajos mayores surgieron infinidad de capítulos de libros y artículos en revistas especializadas y de divulgación de la ciudad de México, de otras partes de la República y del extranjero. Pero también elaboró trabajos especiales para enciclopedias y libros colectivos de índole temática. Todos son de una factura impecable. Don Luis se respetaba tanto a sí mismo, a sus colegas, estudiantes y lectores, que sus textos son de una rigurosidad, claridad y calidad ejemplares. También fue muy profusa su participación en reuniones académicas en calidad de organizador, ponente, comentarista, participante de mesas redondas así como conferencista ante públicos especializados y no tanto en México y en muchos otros países. Durante ese tiempo se hizo cargo, entre 1960 y 1964, de la revista Historia Mexicana y de la dirección del Centro de Estudios Históricos de El Colegio de México de 1963 a 1965.

En esa vorágine de obras y compromisos andaba cuando decidió dar un giro en su vida y su trabajo. Como es bien sabido, en 1966, acompañado de su esposa doña Ar- mida de la Vara y de sus seis hijos, regresó a San José de Gracia para pasar su año sabático, el pueblo del que había salido hacía 28 años pero al cual nunca había dejado de acudir con frecuencia. Quizá esa sea otra de las singularidades de don Luis. Él, a diferencia de muchos de los emigrantes del mundo rural, mantuvo lazos estrechos e ininterrumpidos con su lugar de origen y también con sus paisanos urbanizados que se dedicaban, con bastante éxito, a quehaceres distintos, como el comercio, y no entendían que "Luisito, siendo tan listo" no se dedicara a los negocios.

Pero además, como hijo único, estaba preocupado por sus padres ya ancianos y achacosos, y pensaba que ese año juntos era una buena manera de acompañar y alegrar su vejez. Pero como evidentemente no podía estar sin hacer nada, emprendió la hechura, de principio a fin, de la microhistoria de su pueblo. La historia es bien conocida. En ese año recopiló datos de los innumerables archivos donde estaba dispersa la historia de los josefinos antes de fundar el pueblo; puso a recordar sucesos a parientes; entrevistó a vecinos; escribió y les leyó, cada semana, a sus paisanos los capítulos en que fue organizando la "historia universal de San José de Gracia".

Lo que sucedió después también es muy sabido. El texto no gustó mucho a sus colegas, pero consiguió el patronazgo del doctor José Gaos, don Antonio Alatorre y don Daniel Cosío Villegas, lo que permitió que se imprimiera y viera la luz pública rebautizado como Pueblo en vilo. Microhistoria de San José de Gracia, publicado por primera vez hacia la navidad de 1968. Y ahí sí el autor y su obra traspasaron las barreras de la disciplina. Pueblo en vilo ganó lectores y adictos más allá del mundo de los historiadores donde su autor era muy bien conocido y reconocido, y se convirtió en libro de texto, en bibliografía recomenda$\mathrm{da}$, en referencia obligada para los estudiantes de diversas disciplinas sociales. Si bien no fue un bestseller, decía don Luis, la historia universal de San José de Gracia, como él gustaba llamarla, tuvo muy buena prensa: amigos, discípulos y extraños lo "piropearon bien y bonito".

Fue un decenio de éxitos. Entre 1968 y 1979 el libro alcanzó tres ediciones que experimentaron algunas modificaciones y al cual fue preciso aumentarle el tiraje: de los dos mil ejemplares de la primera edición se pasó a 
tres mil en la segunda y a seis mil en la tercera, algo verdaderamente inusitado para un trabajo de índole académica. En 1971 Pueblo en vilo recibió el premio Haring de la American Historical Association. En 1974 fue traducido al inglés como San José de Gracia. Mexican Village in Transition por la Universidad de Texas. En 1977 apareció en francés con un título que retomó una hermosa frase del libro: Les barrières de la solitude, editado en París por la editorial Plon. El espíritu de don Luis, decía el mismo, "se puso tan gordo como su cuerpo... y el exceso de masajes al ego... [le había servido] de rémora y de acicate”.

En la década de 1970 y a pesar de que la microhistoria iba ganando terreno en su quehacer académico, le tocó hacerse cargo de la armazón y el seguimiento de otra obra nacional de carácter colectivo y de gran envergadura. Don Daniel Cosío Villegas, ya añoso, le entregó la coordinación académica del "Seminario de historia de la Revolución mexicana”, es decir, la tarea de encabezar y encauzar los trabajos de cincuenta investigadores con el fin de elaborar la colección de Historia de la Revolución mexicana que publicó El Colegio de México en 23 volúmenes de "poco bulto... muchas fotos y otras ilustraciones”. Don Luis, fiel a sí mismo, no sólo fue coordinador de esos trabajos sino, además, autor de dos de los tomos de esa colección: Los artifices del cardenismo y Los días del presidente Cárdenas.

Varias de las grandes obras, individuales y colectivas, en las que participó correspondieron a solicitudes especiales de la presidencia de la República o del poder legislativo. En todos los casos, su mirada crítica e irreverente, pero siempre justa, contribuyó mucho a que esos trabajos lograran escapar de la historia de bronce y se convirtieran en obras que, a partir de una revisión fresca, certera, original, creíble del pasado mexicano, siguen siendo trabajos claves e imperecederos para las ciencias sociales y las humanidades.

Pero ya la microhistoria lo perseguía y le exigía. De todos los frentes le llegaban solicitudes para que hablara y escribiera sobre lo que se debía entender y cómo se debía hacer una microhistoria y para que confeccionara más estudios de esa naturaleza. En 1971, por encargo del Banco de Zamora, escribió La tierra donde estamos, que adjetivó como "Apuntes de historia regional y local del occidente mexicano". En 1973 se publicó, en la colección SepSetentas, Invitación a la microhistoria, donde reunió varios trabajos anteriormente dispersos en torno al tema. Pero también, "más de fuerza que de grado", decía, había vuelto a la investigación microhistórica al encargarse, por cuenta del gobierno del estado de Michoacán, de la coordinación de la historia de los municipios de esa entidad. El resultado fue la colección de 23 monografías de otros tantos municipios. De la confección de dos de ellas se encargó el propio don Luis: Zamora y Sahuayo que acabaron por darlo a conocer entre la gente de esa región que corresponde a los rumbos que han formado parte de los tránsitos y querencias de los josefinos.

Poco después se encargó también de coordinar, por encargo de la Secretaría de Educación Pública, la hechura de las monografías de los estados de la República. En este caso también, él se echó a cuestas la tarea de elaborar la de su propia entidad, de confeccionar el libro que se llamó Michoacán, lagos azules y fuertes montañas.

\section{DESPUÉS DE 1979}

Cuando estaba saliendo de varios de esos pendientes le llegó la oferta de crear lo que desde el 15 de enero de 1979 se llamó El Colegio de Michoacán (Colmich), en la ciudad de Zamora, que sólo a él le gustaba. Desde una vieja casona en la calle de Madero y el café del mismo nombre fue dando forma y definiendo el rumbo de la flamante criatura. Sin abandonar sus labores académicas tuvo que dedicar tiempo, esfuerzo e imaginación a la gestión.

Aunque no lo parecía ni lo presumía, sabía muy bien lo que quería y era obstinado en las cuestiones claves. Con mano firme, pero delicada, dejó claro desde el principio que el Colmich era una institución cercana y afín, pero independiente, de todas las que lo habían patrocinado; que él se iba a encargar de escoger a sus colaboradores y definir sus tareas; que se trataba de una institución de docencia e investigación donde los profesores-investigadores tenían que ejercer el oficio y los estudiantes aprenderlo, junto con ellos, en la asistencia y revisión de documentos en archivos, bibliotecas, hemerotecas o en el trabajo de campo realizado en el mundo rural y las 


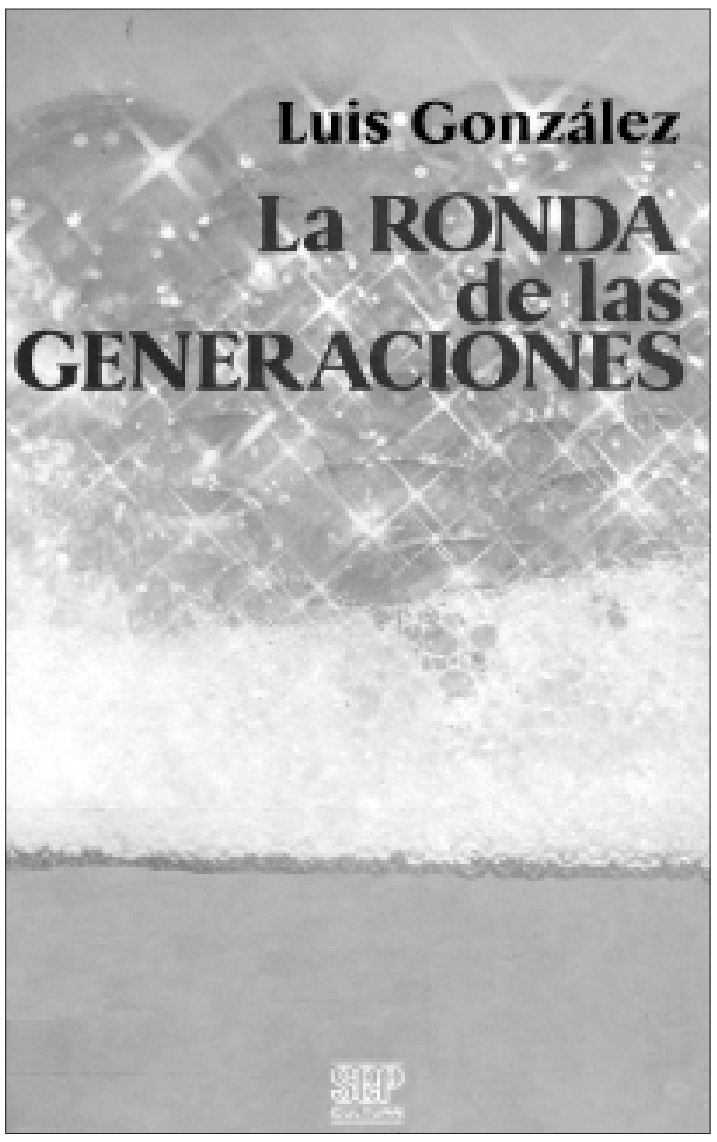

ciudades; que se debía trabajar en seminarios, sin descuidar el trabajo personal; que había que tener una estupenda biblioteca donde explorar y trabajar sin excusa; que era imprescindible, desde el principio, producir una revista que diera cuenta de los avances de las investigaciones; que era necesario diseñar un consejo técnico donde se pusieran a discusión y reflexión los asuntos comunes. Don Luis tenía una capacidad asombrosa para llegar al meollo de los problemas y proponer soluciones atinadas donde otros veíamos obstáculos insalvables o peripecias infinitas.

Por si fuera poco, los informes anuales de don Luis acerca de la marcha de El Colegio de Michoacán eran esperados por todos: él, como nadie hasta ahora, sabía transformar cifras y listados de logros y pendientes en textos de tanta frescura, buena prosa, simpatía, respeto que nadie quería perdérselos y las risas se oían por todos los corredores de la vieja casona de Madero.

Aunque siempre privilegió la investigación sobre Michoacán, aceptaba de buen grado el interés por otros espacios. Su curiosidad y conocimientos acerca de lugares y aconteceres de otros tiempos eran tan grandes que casi nada le era ajeno, a todo le descubría un ángulo interesante. La vieja tradición de estudios históricos y antropológicos — sobre todo acerca de los purépechas-que existía en Michoacán fue nutrida y continuada de manera ejemplar por la labor de los estudiosos que se habían vuelto colmichianos, algo de lo cual pocos estados pueden presumir.

Ese hincapié en la entidad ha contribuido, sin duda, a que Michoacán sea, hoy por hoy, uno de los estados mejor investigados del país en lo que se refiere a ciencias sociales. Como se sabe, a los centros pioneros, el Centro de Estudios Históricos — al que él mismo fue de los primeros en sumarse como profesor-investigador - y el Centro de Estudios Antropológicos, nutrido por investigadores del CIESAS y la UAM-Ixtapalapa, se añadió, poco después, el Centro de Estudios Rurales y, más tarde, el Centro de Estudios de las Tradiciones que conformaron los cuatro primeros programas de investigación y posgrado que tuvo el Colmich durante muchos años.

El café - costumbre que importó de manera deliberada del Colmex y mantuvo durante todo el tiempo que fue presidente del Colmich - desempeñaba un papel clave en la vida de la institución. Las once de la mañana de cada día era el momento para empezar a reunirnos, a veces con visitantes, a veces solos, a comentar noticias de toda índole, a intercambiar ideas, a tomar acuerdos, precisar eventos, estar juntos. Allí se reencontró con amigos de todas partes que llegaron a conocer el nuevo Colegio y que ayudaron con cursos y seminarios y difundieron a los cuatro vientos la existencia de esa nueva y robusta criatura académica, como gustaba de llamar don Luis al Colegio. Cuando él no estaba también íbamos al café pero hacía falta. Esperábamos su regreso, por lo regular acompañado de buenas noticias o, al menos, así las hacía parecer con su optimismo a toda prueba. Los problemas se ventilaban y solucionaban en su pequeña oficina $o$, mejor aún, en las tardes, en su casa, con más café. 
Don Luis ejercía una pedagogía peculiar: en vez de una orden, prefería contar una pequeña historia, relatar cómo habían resuelto situaciones similares don Daniel Cosío Villegas, don Agustín Yáñez y tantos otros a los que había conocido o de los cuales había leído. No lo asediaba la prisa en la resolución de los problemas. Quizá por esa creencia en los ritmos de la vida prefería dejar pasar el tiempo a tomar decisiones apresuradas. Contaba que don Agustín Yáñez, en su escritorio como gobernador de Jalisco, tenía dos gavetas; en una depositaba los asuntos que el tiempo se encargaría de arreglar; pero en otra, señalaba sonriendo, estaban los que el tiempo no había podido resolver. Con su fina capacidad de observación mantenía y cultivaba una característica muy josefina: la elaboración de imágenes certeras acerca de los atributos y debilidades de las personas que, por lo regular, le recordaban a otras. A partir de ellas entendía, explicaba, disculpaba casi todo. Sólo la deshonestidad, la mentira, la flojera le resultaban muy difíciles de digerir. Pero pocas veces hablaba de eso.

De acuerdo con la ingeniería de don Luis, los que desempeñaban temporalmente cargos de jefes y coordinadores ganaban sólo un poco más que los investigadores para que no cupiera duda acerca de dónde estaba el trabajo sustantivo de la institución. Su salario como presidente era apenas superior al de los que lo seguían y gastaba parte de él en asegurar que todo marchara bien. Al principio, sobre todo, no fue fácil. Más de alguna vez tuvo que pedir dinero a riesgo propio para que los investigadores $y$ trabajadores recibieran sus quincenas a tiempo $y$, desde luego, sin que se enteraran de las tribulaciones por las que pasaba para ello. Era la cartera más rápida del Colmich. Los viernes, después de alguna conferencia, actividad que sólo se interrumpía durante la temporada de lluvias que por Zamora son de verse, solía invitar al conferencista y a los colmichianos a merendar al Café Madero, donde la cuenta corría, invariablemente, de su propia cuenta.

Y es que era, además, infatigable. Cuando nos encontrábamos en el café él llevaba a lo menos cinco horas de trabajo: las de sus madrugadas insomnes donde leía, reflexionaba, hacía esquemas, escribía, y las que había dedicado a resolver los mil y un pendientes que había que enfrentar y resolver para consolidar al Colmich en los mundos profanos y académicos de Zamora, Morelia o la ciudad de México. Él procuraba hacer lo más que podía solo, sin causar molestias y distracciones a los demás. A veces no era posible. De madrugada entonces salíamos rumbo al Distrito Federal, Morelia, Guadalajara, Colima o donde fuera necesario a desatascar trámites, presentar proyectos, conseguir apoyos y patrocinadores para algún propósito, para asistir a reuniones y eventos imprescindibles, muchas, tantas veces, a "pasar la charola" como le llamaba a las reuniones con funcionarios para convencerlos de la bondad de tal o cual iniciativa y que se autorizaran los presupuestos. Como era excesivamente puntual, invariablemente llegábamos antes de la hora a las citas, lo cual le complicaba la vida a secretarias y asistentes que se dedicaban a atiborrarnos de café, té, agua y galletitas.

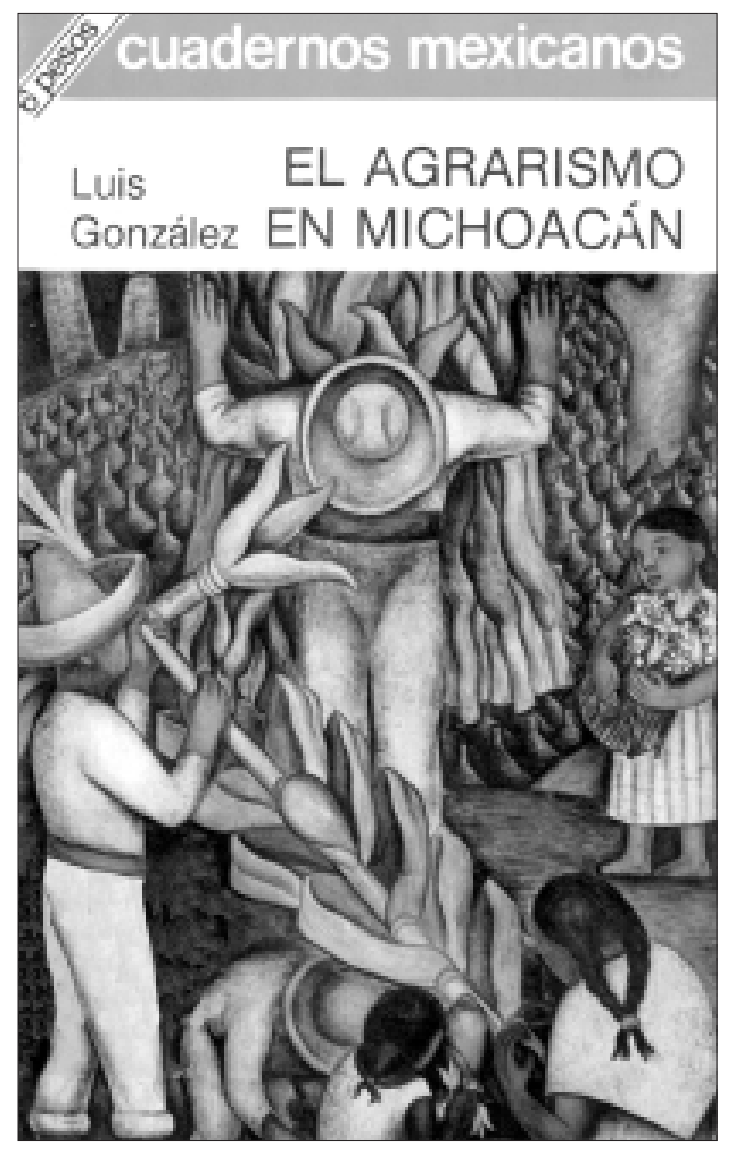




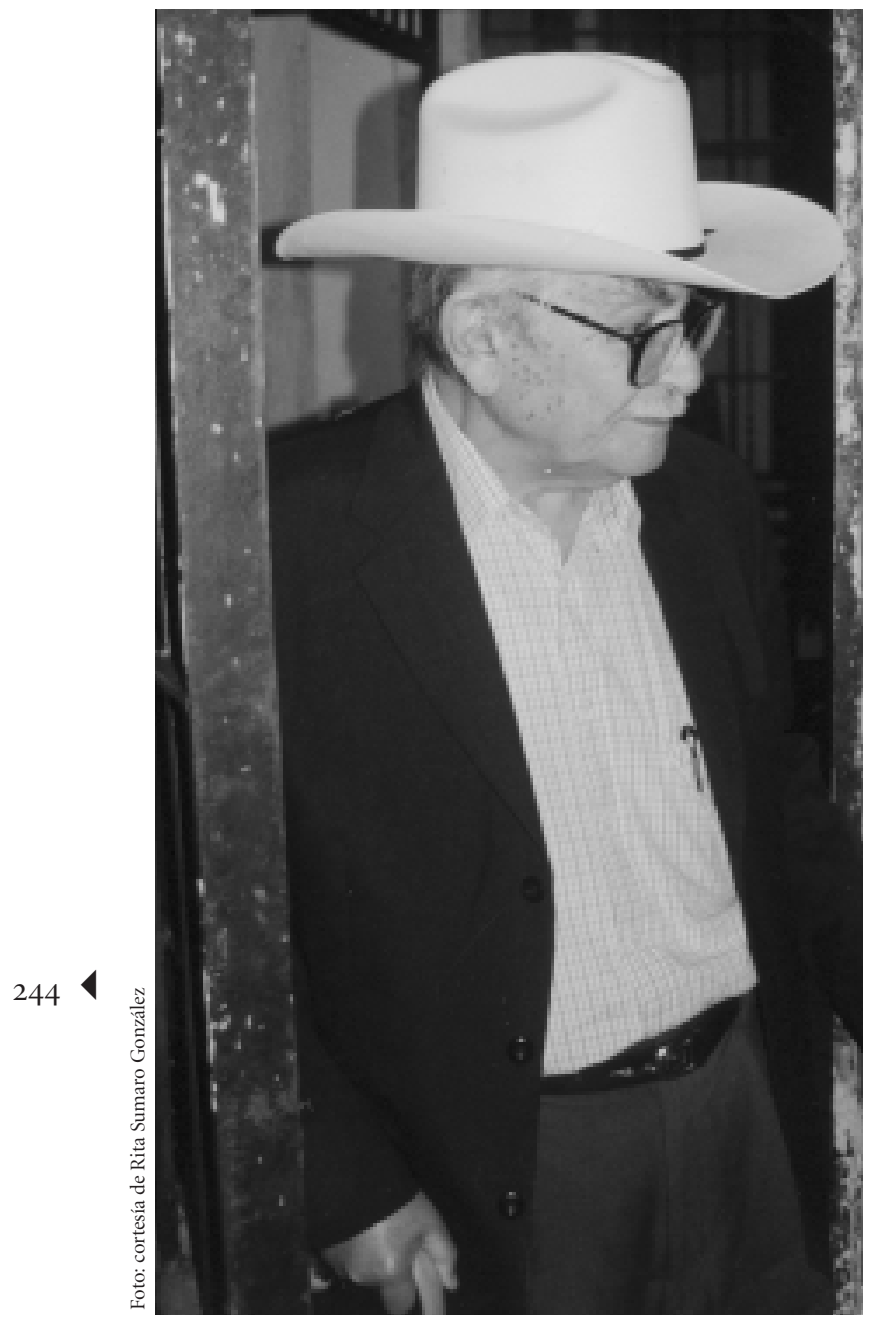

Don Luis, con amabilidad, con una sonrisa y alguna pregunta inteligente, disolvía el desafecto y convertía a su interlocutor en su aliado para la siguiente visita. Jamás dejaba de saludar al personal de las oficinas por donde transitaba y no faltaba quien lo reconociera y se admirara de la sencillez que hacía más notable su fama. Sabía relacionarse con los funcionarios. Era afable, simpático, pero sin dejar de insistir en los objetivos académicos, en el motivo preciso de la visita. Generaba certezas e inspiraba confianza. Hasta tal punto que más de alguna vez salimos de una dependencia con el cheque en mano y el compromiso verbal de justificarlo más tarde, además del susto y la sorpresa. Su mirada transparente convencía y era la mejor garantía de que lo que decía era verdad. Se sabía muy bien: don Luis era honesto hasta en las conductas más pequeñas.

Quién sabe cómo se enteraban sus amigos, colegas y discípulos del Colmex y de otros lados, pero apenas llegaba a su casa en la ciudad de México, lo esperaban un sinfín de llamadas telefónicas que él convertía en invitaciones a desayunar, comer, a tomar café, a merendar. Su esposa Armida, sus hijos y Evelia se afanaban para que la estancia de los invitados, de todos los estilos, fuera agradable y sabrosa. En esos viajes a la ciudad de México don Luis se convertía en un torbellino de energía inacabable: hacía gestiones; acudía a citas y reuniones; atendía visitas hasta horas tardías, platicaba, escuchaba. Lo impulsaban el cariño y el gusto por ver a sus amigos así como el férreo compromiso con el robustecimiento del Colmich.

Y regresaba a Zamora a una vida pausada y ordenada. Madrugadas de intenso trabajo, mañanas en el Colegio resolviendo asuntos, café de las once, otro poco de oficina, comida temprano, no más de las dos de la tarde, una siesta corta, más trabajo en sus investigaciones o en los asuntos que le llevábamos, cena y una desaparición nocturna bastante temprana. Era una persona de pocos placeres y distracciones más allá de los libros. Los fines de semana gustaba de ir a San José de Gracia, sobre todo si tenía visitas. Acercándose a su terruño siempre hacía bromas acerca de ¿̨uál será ese pueblo maravilloso que se ve allá? En la hermosa casa de doña Rosa o la casa-rancho de don Bernardo se convertía en tío, compadre, sobrino, padrino, esas identidades que siempre cultivó y que le ayudaban a no perder piso, a no subirse a la historia de bronce, a no creerse la fama que lo acompañaba ya casi a todas partes. En 1983 obtuvo el Premio Nacional de Historia, Ciencias Sociales y Filosofía, entre otros reconocimientos a su labor académica.

En los años colmichianos dedicó buen tiempo, aunque quizá menos que en el Colmex, a la docencia en sentido estricto. Entre otras cosas porque decidió que las diez conferencias anuales que El Colegio Nacional sugiere impartir a sus miembros, él las iba a dar, de preferencia, en instituciones educativas fuera de la capital, lo que le llenó la agenda de compromisos y viajes a distintas univer- 
sidades y centros de estudio del país, donde estudiantes de todos los niveles y diferentes disciplinas tuvieron la oportunidad de escuchar de viva voz qué era y cómo se cocinaba, solía decir, la microhistoria.

Siempre autocrítico, decía que en esos años había escrito y publicado menos de lo que hubiera querido, pero su bibliografía arroja un saldo muy positivo: de asunto microhistórico se publicó, en 1982, Nueva invitación a la microhistoria y en 1986 se reeditó, "bastante cambiada" aclaraba, Invitación a la microhistoria. En 1984 salió a la luz La ronda de las generaciones, libro erudito y ejemplar en conocimientos e ideas acerca de las minorías rectoras de México a lo largo de un siglo; ese mismo año apareció El entuerto de la Conquista, donde los sesenta testimonios que incluye van precedidos de un imprescindible y sabio prólogo. En 1985 publicó Once ensayos de tema insurgente, selección de trabajos "hechos en muy diferentes épocas y circunstancias" pero reescritos para la ocasión que era festejar el 175 aniversario del Grito de Dolores. En 1986 salió, en la colección Cien de México, Galería de la Reforma, para el cual escribió el prólogo que introduce y explica la selección de 45 testimonios sobre Benito Juárez. Vistos desde la barrera de los no historiadores, los libros de esos años destacan como trabajos de madurez, sedimentados en la erudición y la reflexión que los convierten en textos imprescindibles que atraviesan las fronteras disciplinarias, incluso académicas, para ser leídos por estudiosos de otras disciplinas del comportamiento social y por quienes quieren conocer, de veras, un México alejado de los estereotipos.

En 1985, fiel a sus principios, dejó la presidencia de El Colegio de Michoacán, "se privatizó lo más que pudo"y, dos años más tarde, en 1987, se mudó a San José de Gracia. Allí, en la enorme, hermosa, añosa y algo achacosa casa de sus padres vivió desde entonces. Al principio tuvo que dedicar algún tiempo a remozarla y añadirle una biblioteca capaz de albergar la inmensa cantidad de libros que él y Armida habían acumulado en la ciudad de México, pero también en Zamora. Don Luis encontraba libros en los lugares más inverosímiles de la geografía nacional, lo que hace que su biblioteca contenga una magnífica selección de trabajos de historiografía, historia, antropología, microhistorias acerca de cada una de las entidades de la
República. Su memoria infinita descubría en segundos y ningún aspaviento, la referencia buscada, el dato que hacía falta. Las rayas pequeñísimas que se encuentran en ellos dan cuenta de sus innumerables lecturas.

Muy pronto se acomodó a su nuevo espacio. El corredor con equipales, la sala, la biblioteca se convirtieron en lugares privilegiados para conversar, aprender, disfrutar de su sabiduría y cada vez más, de su bondad y generosidad sin límites. Le gustaba que los visitantes, de todos los linajes, se sintieran cómodos y bien recibidos. Y lo lograba.

Desde San José siguió acudiendo a reuniones y cumpliendo, sin falta, sus compromisos con El Colegio Nacional, que lo llevaron por distintos rumbos y públicos del país en plan de conferencista, con El Colegio de Michoacán, con la Academia Mexicana de la Historia de la que fue presidente, con el Sistema Nacional de Investigadores, con las juntas de gobierno y comisiones académicas de las que formaba parte en instituciones de la ciudad de México y otras partes. Su fama de ecuanimidad, buen criterio, bondad eran tan grande como su prestigio académico. En 1991 fue nombrado profesor-investigador emérito de El Colegio de México.

$\mathrm{Al}$ mismo tiempo, siguió trabajando, y mucho, en lo que de veras le agradaba: escribir, hacer libros. Para empezar, se empeñó mucho en poner por escrito sus saberes y reflexiones acerca de la historiografía. El más novedoso fue un libro que él apreciaba mucho y que escogió para inaugurar sus obras completas: El oficio de historiar, publicado por primera vez en 1989 que reúne y sintetiza las lecciones de teoría y método de la historia que había impartido en tantas ocasiones; libro que, sin ruido pero sin pausa, ha acumulado ediciones que se agotan con la misma rapidez con que se reeditan. Sin embargo, reconocía don Luis, era una de sus obras menos comentadas. Ese mismo año se publicó además el volumen Todo es historia, una recopilación de trece ensayos de muy diferente data, motivo y tipo de publicación que tienen que ver, por una parte, con el quehacer historiográfico; $y$, por otra, con la historia de México. En 1994 hizo su aparición un texto imprescindible de la investigación regional: La vuelta a Michoacán en 500 libros, vástago, decía don Luis, de su "vicio bibliográfico" y que había sido confeccionado en "los ratos de fatiga de un lustro semejante a un lomerío". 
En plan de difusión escribió un libro hermoso: $M i-$ choacán, muestrario de México, publicado en 1991, que se entregó como un regalo a los clientes de Banca Promex, donde dio rienda suelta a su interés por pensar y relacionar la variedad de los paisajes con la diversidad de las sociedades que los habitan, con las microhistorias que le han dado sentido e identidad a ambos.

A pesar de los achaques que habían comenzado a asediarlo tanto a él como a Armida, su compañera de toda la vida, no cesaba de trabajar y publicar. En 1996 apareció lo que fue su última obra mayor, el libro Jerónimo de Mendieta. Vida, pasión y mensaje de un indigenista apocalíptico. El interés por ese misionero franciscano puede rastrearse hasta muy atrás, hasta los años escolares de don Luis en El Colegio de México. Lo hizo por gusto, como un homenaje quizá al fraile que no era "divertido, radiante o estruendoso... hombre de poca materia y mucho espíritu" al que consideraba "un politólogo e historiador de fuste".

Durante ese tiempo revisó, elaboró los prólogos y colaboró sin descanso hasta que vio aparecer, uno tras otro,

\section{Bibliografía}

Aguilar Camín, Héctor, 1977, La frontera nómada. Sonora y la revolución mexicana, Siglo XXI, México.

—_, 2004, "Luis González y González: una memoria personal”, Nexos, núm. 313, enero, pp. 9-12.

Castañeda, Carmen, 1984, La educación en Guadalajara durante la Colonia, 1552-1821, El Colegio de Jalisco-El Colegio de México, México.

Cosío Villegas, Daniel (ed.), 1956, Historia moderna de México. La República Restaurada. La vida social, Luis González y González, Emma Cosío Villegas y Guadalupe Monroy (autores), $1^{\mathrm{a}}$ ed., Hermes, México.

Florescano, Enrique, 2003, "Evocación de Luis González", La Jornada, 27 de diciembre.

González, Luis, 1978, Curriculum Vitae. La historia académica y el rezongo del público. Contestación por Silvio Zavala, sobretiro de la Memoria de El Colegio Nacional, El Colegio Nacional, México, pp. 163-211.

—_, 1993, "Minuta de viaje redondo", en Jean Meyer (coord.), Egohistorias. El amor a Clío, Centre d'Études Mexicaines et Centroamericaines, México, pp. 57-81.

—, 1995-2000, Obras completas, XVI vols., Clío, México.

Krauze, Enrique, 1976, Caudillos culturales en la Revolución mexicana, Siglo XXI, México. editorial Clío. Así fue fiel hasta el final a lo que un día había manifestado como deseo: que esperaba "en lo restante del camino, leer, escribir y platicar sin estorbos de dirección o de lucimiento".

La dolorosa muerte de Armida en 1998 y la intensificación de sus propias dolencias le mostraron que había comenzado a transitar por su último ciclo. Empezó entonces a recordar con inquietante frecuencia los días y sucesos que precedieron a las muertes de su padre, don Luis, y de su padrino, el padre Federico. Y no opuso resistencia.

No alcanzó a realizar dos proyectos ya incluso bautizados: México en un jarrito y Egohistoria de un fraile menor. Pero no hay que lamentarlo. Lo que dejó fue más que suficiente para leerlo una y otra vez, para admirarlo más aún, para extrañarlo siempre. 